\title{
MENTAL DISTURBANCES ASSOCIATED WITH ACUTE ARTICULAR RHEUMATISM
}

BY ROBERT H. HASKELL, A. B., M.D.,

First Assistant Physician, State Psychopathic Hospital; Instructor in Psychiatry, University of Michigan.

(From the Psychiatric Clinic, University of Michigan, Ann Arbor, Mich.)

The subject of mental disturbances associated with or dependent upon definite physical disease is always of great interest. When the two patients whose histories follow were admitted to the Psychiatric Clinic of the University of Michigan during the month of July, 1913, we were immediately struck by the fact that acute articular rheumatism as an etiological factor had not been represented up to that time among our exogenous psychoses.

The question of the specificity of symptomatic psychoses is one that is still debated. At one extreme is Siemerling, who believes that we cannot differentiate exactly the various forms of mental disturbances arising during the course of infectious diseases from one another, let alone from other disease pictures. In an intermediate position stands Bonhoeffer, who grants that there are certain reaction types in exogenous psychoses, but yet feels that they cannot be clearly separated according to the preceding infectious disease. At the other extreme is Kraepelin, who writes: "Even though at the present time I can say little to dispute incontrovertibly these opinions, I am none the less convinced that we will some day have to recognize not only the integrity of the infectious psychoses in general, but also be able to diagnose different types as they develop during the course of the different infections from their psychical manifestations." His point of view, at least as far as acute articular rheumatism is concerned, is very strongly supported in a recent exhaustive study of the subject by his one-time assistant, A. Knauer, who has gone over the clinical material of the literature very critically, called out many cases as non-usable and added 12 new cases.

With this question still sub judice we must be very critical in the selection of cases that we place in this category. The mere fact that a patient who either has, or has had recently, an acute infec- 
tious disease, shows signs of mental disturbance does not necessarily mean that this psychosis is dependent entirely upon this infection. The psychosis may have existed prior to the infection, or it may be of a purely endogenous type and in this case stand only in a secondarily etiologic relation to the physical disorder. The latter relation we see particularly frequent in cases of dementia præcox and manic-depressive insanity. Likewise a concurrent incident, such as uremia or a delirium tremens, which develops during the course of an acute infectious disease, should not be mistaken as a mental disorder dependent upon the infectious disease in question. If these general principles are firmly adhered to, many cases described as mental disturbances dependent upon acute articular rheumatism, particularly those from non-psychiatrical hands, will have to be thrown out of consideration. One great drawback to a complete understanding of many of these cases is the loose use of general terms and an inadequate description of the symptoms present. For that reason we have deemed it advisable to present the clinical history of our two cases in considerable detail.

J. H. S., farmer, aged 42. Family history negative. Four healthy children. No alcoholism. General medical history unimportant until ten years ago, a severe attack of acute articular rheumatism lasting four or five months. In the last four years rheumatoid attacks each spring.

In June, 19r3, another definite attack of acute polyarthritis. He was in bed only two weeks and then went to a neighboring town to take mineral baths. He here had a short relapse of his rheumatism, but began to improve again until by July 17 he had been free from joint symptoms for several days. Then, without premonition, he suddenly complained of the "queerest feeling in his head as if something shot through it just like lightning," and for three days following spoke of a dull pressure in his head. On the 2oth the rheumatic pains again appeared in his leg, his ankles became swollen and then his hip joint became affected. On the 22d he fainted during the bath. On the 23d he was found crying, was drowsy and said little. That evening he became very talkative, repeating over and again some imaginary conversation he had had with his wife and sister the night before concerning his death. He had some realization that things were not right with his mind and said, "I know there is something here (pointing to his head), but don't know what to do to get rid of it." For the next few days he spoke often of his going to die, was moderately restless and had at times auditory hallucinations. He was admitted to the Psychiatric Clinic as a voluntary patient on July 28 , 1913, five days after the development of distinct mental symptoms. 
On admission he had a temperature of $100^{\circ}$ by axilla, pulse of 100 and respiration of 18 . Physically he was a raw-boned farmer, somewhat undernourished. His skin showed a dirty, yellow, cachectic color. Mucous membranes pale. No swollen or painful joints. His heart was slightly enlarged and showed a loud systolic murmur at the apex which replaced the first sound. Blood pressure was II6. Blood count showed 4,000,000 reds, 13,500 whites and 75 per cent hemoglobin. The neural examination was unimportant. A blood culture and a urea estimation were made by the Medical Clinic of the University Hospital which reported negative findings in both instances. Urine was acid, sp. gr. IO2I, negative for albumin and sugar, with a few granular casts in the sediment. Wassermann examination on the blood was negative.

He was rather suspicious and apprehensive and took a very lively interest in everything about him. His consciousness was clear, but his train of thought was considerably disjointed. "I died half a day ago. I bet you I was all cold and stiff and they warmed me up." (Are you in Heaven?) "Yes, I think so. I been here a couple of days. I'm nicely arranged here. No, I only came here this morning. Can you fellows test my blood?" (What are you going to do here?) "You let me lie here fifteen minutes and see what I'm going to do. You got me warmed up. Put me in a tub of cold water. I'm dead now." (Are you sure you're dead?) "I can't tell if I'm dead or not-my wife is dead and my sister." (When did they die?) "She ain't dead yet. Who's that screaming out there? That's my wife." (How did you die?) "I was in the hospital over here." (What hospital?) "Ann Arbor Hospital." (Did you die there?) "I died right at home. You let me lie here for an hour and cool. I'll bet you anything-." Here he closed his eyes and pushed the clothes away from him apprehensively. (What's the matter?) "I haven't got a heart in there; it's been quiet for four hours. You got me warmed up. You take me over there and get my perspiration started and press a button." (What's the button for?) "To kill people. I've got my eyes shut to give you the chance." (I thought you were dead?) "You put me in a bath tub and let me cool off." He would lie quietly in bed for short intervals, then become restless and talkative, call out to his wife, who, he thought, was being detained in an adjoining room and make forceful attempts to go to her.

For the next few days his axillary temperature continued around $100^{\circ}$. He remained quiet as long as left alone, but would become suspicious and frequently resistive at any examinations made. He would answer few questions. He was mildly stuporous and expressed his unclearness in such ways as " they began to mix things-I don't know-I'm J-S-, but things got kind of mixed up-and-well, I don't know." He would then become muddled in saying the alphabet and then realizing his inability to make such tests would refuse to talk any more. On the 4th it appeared certain from his suddenly sitting up in bed and listening intently that he was hallucinated, but he would not admit this. No experimental visual hallucinations could be elicited by pressure on the eyeballs. He spoke of his "acting 
kind of funny, but everything around here is kind of funny and I can't understand why the people here should look at me so suspiciously." During the following five days he gained in strength, ate very well and reached a point where he would talk freely about his sickness in a very logical way, explaining his suspiciousness as due to fear, but yet at the same time refusing to co-operate in any detailed psychological examination. On the afternoon of the gth, following a pleasant visit with his wife, his temperature rose to $99.2^{\circ}$ by axilla, higher than it had been for five days : the next morning it was $99.4^{\circ}$ and that evening $99.6^{\circ}$.

During the afternoon of the roth he became confused, somewhat more apprehensive, would regard each attempt to take his pulse and temperature as a sinister move and frequently refused. He ate very little. That night he was on the move constantly, but saying little. On the IIth he was afraid he was going to be killed, and would not step on the scales for fear of electricity. He sat on the edge of his bed, looking with extreme apprehensiveness from one corner of the room to the other, particularly at a ventilator opening, through which perhaps he heard the voices of some of his family, and he frequently would lift up the sheets and blanket or bend over the side of his bed suddenly to search for his children. His attention showed considerable distractibility, but not sufficient to let his train of thought be led from the main idea: his children and what was going to become of them after his death.

That night he slept five hours and at the morning visit was found reading a paper. He dismissed his experiences of the preceding day with the simple statement, "I guess it was only my imagination." He showed no thought disturbances in his conversation, read a paragraph aloud without error and related its contents correctly and in detail.

On the evening of the $13^{\text {th, }}$ when the other patients were asleep, he called to the physician, and after looking about the room carefully to be sure no one was paying attention, wanted to know "what underhanded mess was on." He slept six hours and in the morning showed the same slightly stuporous state.

On the 15 th, following a visit of his wife, he was discouraged and sad. On the 16th he became gradually more restless, left his bed and, tiptoeing to and fro in his room, would whisper confidentially "just a minute-just a minute-you just wait and see," suddenly bending down to look into the ventilator, as suddenly darting around the corner, only to come back to repeat the performance. As the day wore on he became more active and fearful, running around the room in all directions. His attention could not be gained except for an instant by strong stimuli, and yet he jumped, startled, at every noise from without. There can be no question about his being hallucinated at this time. He said later he saw some children in the room and believed that we thought he was going to kill them. He slept but little that night. The next morning he lay quietly in bed. He had little remembrance of the day before beyond that he thought some harm was coming to his family. He evaded questions, would talk 
about his early sickness in a rambling sort of way, leading into inaccuracies, but each time correcting himself. He realized the increased inaccuracies that came with fatigue and refused to talk long.

He continued quietly in bed for two days, but on the afternoon of the Igth became more unclear and inaccessible; would take no nourishment, and refused to have his temperature taken.

On the zoth, following a fair night's sleep, he lay on his bed talking incessantly; the main theme was the numerous changes that had been made during his residence, in which he surprised one with the accuracy of his memory and also with his knowledge of the names of the other patients, attendants and doctors, which, from his constant suspiciousness, it was very rarely possible to test with any degree of satisfaction. There was a certain amount of distractibility in his talk as one patient or another, passing his open door, would furnish the stimulus, but it quickly came back to the original theme: the same questioning why things should be so mixed up. During the day he became less talkative, more restless and again fearful of some great harm. He said he "would rather be shot, lynched and skinned alive than suffering what he was going through." Noises from outside he would interpret as coming from the ceiling or walls of his room and would run in all directions to escape them. He became destructive of his clothes in an endeavor to protect himself and early in the evening, when the attendant's back was turned, rushed out of his room and smashed a window light in an attempt to escape. He continued fearful, protecting himself behind his mattress at times, keeping close track of numerous black objects on the walls and floor and, when they were suddenly suggested, brushing them from his person. "No one could blame me for breaking the windows to escape from being turned into a black man." He gradually became quieter and slept from midnight on. He had but little remembrance of the happenings of the day before beyond that he believed he was in prison and that his wife had come in an automobile, of which he probably heard many outside, and that we would not let her take him. This morning she came to visit him; he confusedly asked, "Why, you're my wife, aren't you? Do you say she wasn't? She is, aren't you, Mama?" He quickly readjusted himself and according to his wife he talked better than at any time heretofore and she couldn't see but that he was well.

He remained quiet and as far as one could observe, considering his reticence, clear, until in the afternoon of the $22 \mathrm{~d}$ he awakened from a nap confused and apprehensive, and in his fright soiled the bed. He quickly gained his orientation, was somewhat chagrinned, but remained a little dull the remainder of the day.

On the 23d he was unusually apprehensive all day and was anticipating dangerous attacks from all sides. He remained mute to all questions as to what caused his fears, but occasionally, as he would cover his head with his bedclothes and cower in an extremely fearful way, he would whisper, "Just a minute, just a minute-now look there," when he would close his eyes and shudder. 


\section{MENTAL DISTURBANCES AND ARTICULAR RHEUMATISM [Oct.}

On the 24th he was again fearful and pulled his bed to pieces to provide himself with protection from threatening attacks. Toward night he became even more delirious, looked anxiously about him in all directions, particularly at the ceiling, and at frequent intervals would cover his head with a pillow, close his eyes and shudder in anxious expectation of some terrible attack, the nature of which could not be learned at the time. He was not aggressive and when pressed to tell of his ideas would pay little attention beyond, "Just a minute, just a minute-now look there," and cower most terrifiedly. He slept not at all that night. In the morning he was decidedly unclear. He asked, "Ain't there lots of valuable stuff around here that someone could use without its being wasted?" What the connection was is extremely uncertain. A little later he said he felt sure that he was going to be burned at the stake. He became clearer after a little rest. He smiled sheepishly when questioned about his conduct of yesterday. "I thought they were shooting niggertine into me: they would inject it into my blood to mix the nationalities. They seemed to be squirting this stuff down through the ceiling. There was kind of a riot like this and seems to me as if we got clear over into Europe and finally there was only so many white people." (Why should they want to inject niggertine?) "I kind of thought while I was around here dissatisfied and my wife wanted me to come home, and you know one day the nurse was dissatisfied and told me it was all imagination, and I said perhaps it was, but he got mad and quit and this tall fellow came. Now I think when I came over here to Ypsilanti the bed set this way and unless I was awfully deranged my bed was that way and the other fellow-the short one-he made the bed and he kind of got disgusted at me and quit, didn't he?" (Where are you?) "Why, I'm in Ann Arbor, in the hospital, ain't I? I thought maybe you were laughing, that I'd done something-that's why I stopped. Well, I was kind of paying attention to them-they was kind of grinning-of course, if you say it's all imagination-of course I don't know-you say this rioting is all imagination-of course I don't know, but it looks like it." He showed the very least distractibility, but finding himself wandering in his remarks, he would pull himself together and start in again. He could follow the alphabet through correctly in good time. He added sevens correctly as far as seventy, where he became undecided as to the correctness of his answers, and proceeded hesitatingly to eighty-four; then becoming more puzzled, he started in again and continued to forty-two, where he stopped with the remark that " $I$, of course, was paying attention, but those fellows was kind of grinning at me." He would make no further attempts. He was "too sick a man to do such things."

During the next three days he became quite clear, read the papers, commented on indifferent subjects, but yet remained always the least bit suspicious. On the 29th, after a sleep of eight hours, he awoke rather dazed, became rapidly apprehensive, fearful of impending harm and spoke of his room being occupied by men whom he hunted under the bed and in the corners of his walls and ceiling. He slept not at all that night, remained 
much the same the next day, but gradually quieted down toward evening when he slept eight and one-half hours and awakened on the 3ist perfectly clear, but with only a very hazy remembrance of the preceding two days. On the following day he was removed from the hospital against advice. Though he had been anxious to go, he became very suspicious when dressed, and even when in the hands of his people continued fearful of some impending danger. After his removal home his condition fluctuated between lucid intervals and the same unclear state that he showed here, without, however, any outbursts of excitement. He gained in weight and strength and in a month's time had entircly recovered from his mental disturbance, about four months after its beginning. He has continued perfectly well and shows no signs of mental peculiarity.

E. M., widow, aged 42. Father probably was arteriosclerotic and died at 76 of heart failure; mother died following an apoplexy at 82 ; family history otherwise is negative. Her life up to the present trouble has been unimportant. During the spring of 1913 she cared for her mother for two months in her last illness and also for her sister during an attack of mastoiditis; nothing unusual in her conduct developed during this period.

In May, following a tonsillitis, she developed acute articular rheumatism. She made a good recovery after five weeks in bed, with no signs of mental disturbance. Her physician did think that toward the last she called him many times when it was unnecessary and that she was fatigued rather excessively by the visits of friends, etc. Her convalescence progressed favorably following a change to her summer home, until early in July she suddenly became very much confused, smeared her face and hands with ink and spoke of herself as no longer being Mrs. M. She was found to have a temperature of $101^{\circ}$, but no signs of any joint involvement were found by her physician. During two weeks in a general hospital she was mildly delirious; spoke of herself as being dead and thought she ought to be buried; all her relatives were dead; everybody had the cholera. Her temperature averaged about $\mathrm{I}^{\circ}$ above normal.

She was admitted to the Psychiatric Clinic as a voluntary patient July 30, 1913. She had a T. P. R. of $100^{2}$, I10, 20. Physically she was well nourished; lungs and abdomen negative; heart slightly enlarged to the left and had a loud blowing systolic murmur at the apex replacing the first sound; blood pressure 138 . There were a few minute spots on the left shoulder which suggested the possibility of petechiae, and which later disappeared in part, but no others reappeared. Neurological examination unimportant. Urine and blood were negative. Ophthalmoscopic examination showed in each eye a slight neuroretinitis, but no gross fundus lesion Wassermann examination on blood negative.

She was somewhat exhausted from a train ride of about roo miles and required assistance in walking. She wore a far-away, dreamy expression on her face, and it required several repetitions before she would attend to questions. Some of these she would then answer promptly in a clear tone of voice; other times she would mutter complacently in an undertone about 
being dead, of being changed into someone else and of someone killing her brother. She was correctly oriented for place and person, but not for the exact date. Toward night, after several hours' sleep, she became mildly restless and as soon as left alone would slip out of bed and wander about like a somnambulist. The next morning she had a clear recollection of her coming to the hospital, though, as so frequently afterwards, she referred to the time interval as seeming so long. She volunteered little during the day. Her answers were fragmentary. The next day, in response to terrifying delusions about her brother and sister having their heads beaten in and bleeding to death, she became extremely agitated for a short while. "I hear them shrieking. No one need tell me. Don't you hear them? I have seen heartless people, but you are the most heartless of all. I can hear you, Rob."

On the night of the 6th she threw a saucer at an electric light nest in the ceiling to liberate three friends whom she saw there, and the following morning she pointed out the dead bodies of two friends in the courtyard. She begged that we bury them, or at least remove them to get rid of the smell. Though at times agitated in expressing these ideas, her attitude now is quite calm. She speaks of herself as having been killed and of having been burned to a crisp with her brother and others in an electric furnace and then pieced together again. The preoccupied, dreamy state continues and it is difficult to hold her attention. It took her four minutes and fifty seconds to perform the A test with 52 per cent errors. Adding tests were impossible; she would grasp what was wanted but seemed helpless to elaborate. Short stories were read to her; she would apparently listen to them carefully, but would return only merest fragments without connection. There was little change until on the IIth she became distinctly stuporous for a few hours; no resistance to passive movements or cerea flexibilitas. She was passing very little urine, only five ounces in that 24 hours, which, however, was free from albumin and casts. The next day following increased fluids her urine rose to its usual amount and the stuporous state entirely disappeared.

There was little change in her general attitude. As long as some one was with her she would remain quietly in bed, glancing about in an unclear, dreamy sort of way. The minute her nurse left her she would slide from bed and wander around. Save for short periods, when she would express terrifying delusions concerning the fate of her relatives, she gave little spontaneous speech. As soon as talked with, she started the same disjointed, unclear recital of how she had been changed, etc., of which the following is a sample.

"There's-aren't you the doctor we met at Ann Arbor? No, you're not. Are you-I thought-no-." (What is it?) "Well, don't put that down. I'm sure-the only way I can tell my real identity is by my feet and hands." (What is your real identity?) "Well, I was Mrs. of - No, oh, dear, don't start that again-was that yesterday that we had such a time?" (Had such a time?) "Um-um-in the first place I was Mrs. — of —_." (Yes?) “But I had the same-well, I had 
the same feet, the same toes, that I have now-well, this is certainly a mixed up affair; perhaps I better leave it where it is-and I went to-I was Mrs. - of and then $I$ went to the hospital and-I mean the hospital-I was there quite a long timeand, oh!"- (Yes.) "I don't see what they're laughing at. Do you?" (Who is laughing?) "Those people out there. Those boys." (At you?) "I don't know-seems as if they must be. Then-let's see what year was it I went to - I was there one season-. I think it was

The trouble is I left my ring in the - Savings Bank-I was nineteen-." (You were nineteen?) "It was in the year $1893-$ I know I was 23 when I was married." (What were you telling me about?) "About children, do you mean-I had four children-and-and-and-." (Yes, now go on.) "Then when I came home from the - hospital-why, my teeth were changed you know-I talked so perfectly terrible." (Yes) "-and, eh, eh." (Yes). "Why, I can't be that one, either-yes, there was only one Mrs. —." (What was it?) "That was only one Mrs. - let's see, how did that go? I know I talked so terribly." (Yes.) "Well, I don't know what just did happen to me, but I know that-oh, for goodness' sake, don't." (Looking as if hallucinated, though it could not be definitely determined.) "Well, when I came back from the hospital, my mother was very sick and my sister-in-law was very sick." (Yes, go right on.) “Well, it isn't so easy to go on, you know. Then I was taken to - - - - oh, yes I-." (What happened there?) "Well, I was taken sick and had to be carried home-." (You were carried home?) "Yes, oh, that isn't-possibly-dear me." (What?) "It's a queer-." (It's a queer what?) "It's a clear mixup-now my hands are just as they were and let's see, who was it straightened my teeth?" (Just what happened?) "That was the time I went to the hospital (And then?) "Oh, I was sick quite a long time and talked terrible." (And where did you go then?) "Oh, from there I went home." (And then where?) "I went down-" (Yes.) "Why no, I'm not a cheat. I don't want to cheat any one, but l'd like to know just what my identity is-the first-summer I was at - - I was 40-or 30." (Where are you now?) "Well, when I got up this morning and looked out I thought it looked like the High School. - Is this Ann Arbor or — ?" (I asked you.) "Well, I don't know. It looks like _."

She has several times given the day correctly, but the date regularly is one week off. She names each of the physicians by the same name which is that of her maid at home. She reads aloud with one unimportant error the Shark Story from Franz, but repeats only, "Why about the steamer and the shark and the streak of blood-I didn't remember what else there was." She could not be influenced into accepting statements which were not there and recognized those which were in the story as they were presented. She copied from dictation Franz's Pig Story, in which the only errors were a rare omission of a small word and a reduplication of a final "ing." Questioned immediately as to the substance of what she had 
written, she replied with a smile, "Pigs is Pigs and Guinea Pigs," and passed it off with having paid no attention to what she had read. She could describe only in a very meagre way pictures shown to her, but questioning again showed that she grasped most of the details correctly. In adding tests she would start properly, but soon began to show long pauses with grossly incorrect results and then break out with something of this sort, "Goodness-don't punish any one on my account." (What were you doing?) "Why, adding sevens." Onuf's card test was explained to her and she kept repeating, "Now it's every seventh one you want," yet she would each time pile up the cards in opposing piles of three or four, or tricks of seven, etc. She appreciated promptly the slight differences in colored yarns shown her and named them correctly. Her attention was easily distracted by little incidental noises and frequently she would precede remarks about her toes and feet by glances in that direction, perhaps caused by fleeting pains.

During September she became a little more unclear. She talked little and spent much of her time standing in a dazed sort of way in the middle of the room, fingering her hands and looking about her inquiringly. She slept practically not at all unless after medication or cold packs. She rarely could be urged to eat and was fed mechanically three times a day. She held her weight and even gained in strength.

There was little change during October. She edged her way through the rooms, occasionally mumbling to herself. One day she was particularly unclear and undressed herself in the hall. She made no defense to pin pricks. She rarely talked. On one occasion she muttered, "I always was so selfish," and then a few moments after, to questions as to what she ate last, answered promptly, "Tube-feeding," and, as if appreciating some humor in the connection, laughed. She would occasionally make some facetious remark to another patient. She would refuse to eat, resist being dressed and then perhaps the same day assist the nurses in some of their duties. On a few occasions she would suddenly stop what she was doing and go into the hall, certainly to attend to some auditory hallucination, but she would not admit them. Not now or at any time was it possible to induce visual hallucinations following pressure on the eyeballs.

The same dreamy, unclear attitude continued into November, but with considerable improvement. Her friends she recognized and questioned them about her home. She was correctly oriented. She said she must have come here some time in July or August. She must have been pretty sick when she came here, but otherwise has no recollection of her conduct or her ideas. Numbers of four integers she could repeat correctly after thirty seconds' intervening conversation. The plumber picture was shown her for ten seconds; she described it as, "I saw a man turning and the water rushing out of the pipes-is that the reason stocks ran down?" (What else?) "That was all-and a lady running away. That's all-isn't it? And the water was scalding the other man." (What was the dog doing?) "I didn't see any dog," and turning the picture over, said, "There 
isn't any," showing by her smile that she appreciated the purpose of the question. The inaccuracies in the tapping experiment had practically disappeared though the time was somewhat lengthened. The form test from Binet was shown her for Io seconds. She grasped the general outline but was unable to complete the details of the drawing correctly. She was given a bunch of keys to count. "Why, you offered them to me once before, didn't you, a long time ago?" Which was so. She counted them as 14 , then 13 , then 15 , until reminded that she failed to include the long one by which she held them suspended, when she said, "Fifteen and this, the master key of them all (marked Master), which makes sixteen." She wrote without hesitation her name and street address correctly. She was removed from the hospital on that day, November 19, 1913, to the Oak Grove Hospital in Flint. Dr. Burr informs us that shortly after coming there she lapsed back into a condition similar to what she had been in here, when she was resistive and refused to eat. Auditory hallucinations became prominent for a time. This passed off in a few weeks when she became more accessible and communicative, gained complete insight into her condition and was discharged from the hospital in February, recovered, seven months from the onset of the mental disturbance.

That a mental disturbance may supervene during the course of acute articular rheumatism was recognized by as early writers as Boorhaave, Van Swieton and Sydenham. A few isolated cases of such complications were reported during the first half of the past century in English, French and German journals of that time. The first study to attract general attention to the importance of the subject was by Griesinger in 1860 . He mentioned the acutely delirious states and commented on their resemblance to the more common deliria associated with typhoid, cholera, malaria and pneumonia, but his main interest in that paper was in the more chronic course of certain cases of a melancholic, stuporous nature, occasionally associated with phases of excitement and rarely with chorea, which appeared suddenly with disappearance of the joint symptoms. Their prognosis was more favorable than the acutely delirious cases, and recovery was more apt to be initiated by a return of the joint symptoms. His conclusion was that these mental disorders ought not to be considered as sequelæ or accidents of convalescence, but that they are only a protracted form of the primary disease.

Casuistic contributions became more numerous, but the next important study was made by Simon from the Hamburg General Hospital. His experience with these cases was very extensive and in three separate papers he records in very useful fashion 29 cases 
of his own, with short but good digests of the 62 cases accessible to him from the literature. Just what factors should have caused Simon to have had such abundant material is hard to see at this distance. Fifteen hundred and seventy-seven cases of acute articular rheumatism admitted to this hospital in the years $1858-187$ I furnished 18 cases of mental disease, or slightly more than I per cent of their hospital admissions of rheumatic fever developed a mental disturbance. He gives figures from the insane hospital at Schleswig to show that of the 78 cases of mental disease dependent upon infectious disease among their total admissions of 2993 , there were 15 cases dependent upon acute articular rheumatism, which means that about $1 / 2$ per cent of all their admissions had this disease as their etiologic factor. These figures appear rather high, especially in comparison with figures from Vienna which show that, in three years of this same period among 600 cases of acute articular rheumatism, not one developed a mental disturbance. It is interesting to note here, however, that Vigla saw in three months of 1853 five cases of rheumatism develop a mental disturbance and only one such case in the whole ten years preceding. From his more extensive material Simon disagreed with Griesinger's idea of a single type of mental disturbance and also attempted to show that these psychoses differ in no way from other post-infectious mental disorders.

The most comprehensive and first really analytical study of the subject is the section on acute articular rheumatism in Kraepelin's prize essay, published in 188I, on the Influence of Acute Diseases on the Origin of Mental Disorders. He was able to collect from the literature 190 cases. After approaching the subject from all possible aspects he separated his material into two big groups, according as the mental disturbances occurred in the febrile period or in the convalescence. Those cases of the febrile period he subdivided into two main groups: the first, or hyperpyretic group, comprising those rapidly coursing cases, usually fatal in a few hours, which come on suddenly in the first week or early part of the second; and the second group, roughly including those cases which present for the most part the usual picture of the febrile delirium. Some of the cases which occurred late in the febrile period, usually after an especially long run of the fever or after several complications or relapses, he grouped, as far as symptomatology and 
etiology are concerned, with the more protracted cases of the convalescent period, a suggestion at this time of his infective-exhaustive states as opposed to the febrile deliria. Kraepelin's studies stimulated numerous case contributions, but the next exhaustive survey of the subject is by Pribram in the Nothnagel system. He comments at length on the entire literature of the subject, but adds little new. He does state that outside of two cases of severe delirium, in an experience at that time comprising I000 personally observed cases of actute articular rheumatism, he had never seen but one develop a prolonged mental disorder, and that one in 1868 .

There are numerous contributions in the French and English literature, but little of a nature to attract special interest at the present time. Joffe in 1908 reported three personally observed cases with comments on twelve cases from the literature. Her particular interest in the matter lay in her bacteriologic studies. American writings on the subject have been exceedingly infrequent. The first that we have been able to find was a clinical lecture by Wood in 1874, in which he merely presents a comatose case of cerebral rheumatism brought back to consciousness by the use of the full cold bath. Da Costa in 1875 wrote from his experience on twelve cases. Unfortunately few of his cases would be so classified at the present day. The next that we have been able to find in the American literature are two short papers by Hoppe and Williams.

We have been particularly interested recently in reading the article by Hewlett, presenting the results of a collective investigation into the therapeutic differences between the natural and the synthetic salicylates, to note the varying appearances of delirious episodes in the cases there considered. Among ten of these cases reported by Withington of Boston, delirium was noted in two and one developed " melancholia," rather a high percentage of complications. The one case with wild delirium was fatal in about twenty-four hours; the mental state was said to be such as one sometimes sees in persons who have taken large doses of the salicylates. What treatment this man had had prior to admission was unknown, but he had had only 60 grains in the hospital. Taylor, of Cleveland, among 16 cases, reported only one delirium. That patient, a man, aged $3 \mathrm{I}$, had been in the hospital in I9I I with a similar attack, complicated by severe mental symptoms, in which he had received over 1000 grains of sodium salicylate without 
becoming toxic. In his second attack of rheumatism in April, 1912, he became "delirious with delusions and hallucinations," apparently recovering in ten days. Dr. Heyn of Cincinnati reports among nine cases of acute articular rheumatism three cases with short and mild nocturnal delirious episodes, apparently of the first grade, and one in which the delirium lasted several days. This last was in an alcoholic individual and was considered delirium tremens. And yet Dr. Warren Coleman of New York, whose patients were in Bellevue Hospital, where one might assume there would be the largest number of patients predisposed by purely extrinsic factors to delirious features, reports not a single case of mental disturbance.

Osler says, in commenting on the five cases of delirium which appeared in his 307 cases, that he thought in at least four of them the salicylate of soda was responsible for the condition and in the next sentence speaks of a peculiar delirium occurring in connection with rheumatic pericarditis which " may" be excited by the salicylate of soda either shortly after its administration or more commonly a few days later. In Taylor's case, the patient in his first attack of rheumatism complicated by severe mental symptoms had received 1000 grains of sodium salicylate without showing signs of toxicity. In the second attack he became delirious after only 60 grains of the salicylate, but the mental symptoms continued for ten days, long after all signs of the salicylate had disappeared from the urine. That the salicylate may have any important influence in precipitating the disturbance, as has been suggested, must be greatly questioned as one goes through the literature and compares the number of cases published before the introduction of the salicylate treatment with their rarity in the journals since that time, and it appears necessary to agree with Lepine, who says that cerebral rheumatism has certainly been less common since the regular and systematic use of sodium salicylate therapy.

Though their fundamental ideas on the subject were quite different, Kraepelin and Simon were not so far apart in their classification. In the study of his 12 cases of the protracted type of mental disturbance, Knauer follows them fairly closely in the separation of his material into four groups.

First. Those cases starting in with an anxious delirious excitement and followed by a phase of melancholic stupor. This class makes up about 43 per cent. 
Second. Those cases showing alternating periods of excitement, stupor and mental clearness. They constitute about 12 per cent.

Third. Those cases presenting throughout their course the mildly depressed stuporous state described by Griesinger. They make 28 per cent of this group.

Fourth. Those cases with an amentia-like state of excitement throughout the entire course. This group forms only 9 per cent.

Our two cases form very excellent samples of this second and third group respectively. As an illustration of the first group, where the beginning phase of an anxious delirium is followed by a period of melancholic stupor, we take the liberty of presenting a digest of one of his cases.

A twenty-year-old shop girl, after a month's course of rheumatism, during which time she voiced numerous hypochondriacal ideas, on May 30, with the outbreak of a severe chorea, shrieked aloud and talked of dying. A few days later she developed hallucinations in all spheres; thought she had become pregnant ; carried on a double conversation with the voices and told of unheard-of crimes that were being committed. Her sentences were fragmentary and disconnected. This state of mild excitement continued for a month, when she became quieter but inaccessible. During August her chorea disappeared. She began to pay no attention to her surroundings, became untidy and gradually passed over into a decidedly stuporous state, where she had to be fed and made no defense to pin prick. By the end of September she had lost thirty pounds. She then gradually began to eat, took some interest in her surroundings, but talked little until the end of October, when she became more accessible. She had a total amnesia for her illnesses, but some insight. She continued to improve physically and mentally and was discharged in December, recovered.

To illustrate the fourth group Knauer himself uses in greater detail the case that Kraepelin presents in his Einführung. Of this we venture the following meagre abstract.

A thirty-year-old white-washer, without predisposing family history or alcoholism, in his fourth attack of acute articular rheumatism. In the fourth week his pains suddenly ceased and he began to talk confusedly. $\mathrm{He}$ expressed ideas of persecution and self-incrimination. Pushed his family away in fear. Prayed much. Became restless and ran about his room. Would not eat and held his urine and bowels. Admitted to the Heidelberg Clinic on the roth day. 
On admission he showed transitory echopraxia, echolalia and catalepsy, but no negativism. His expression was impassive. He answered only after repeated questioning. He was approximately oriented. He shortly developed auditory hallucinations, which continued prominent. The voices were usually threatening and of a deprecatory character. His general attitude varied from a mildly depressed state, when he would lie in bed, more or less inaccessible, to a varyingly agitated condition, ranging from mild yammering to violent running about, knocking on doors and even striking those about him. His perception was usually acute and accurate, but his elaboration was very faulty. Though told repeatedly where he was, he could not quite grasp the situation. He spoke of himself as "being bewitched." In talking he would usually get mixed up and quickly commence to yammer a disconnected tale in which past experiences, his delusions, present incidents, recent remarks and comments on his surroundings were all mingled. Continuous mental efforts in reckoning, etc., were impossible. He expressed various ideas of self-incrimination and persecution. He held himself responsible for a murder being featured in the newspaper. Though giving good reason why he didn't want his tongue stuck or his fingers cut off, he was helpless to protect himself. His condition continued so for about three months, when he began to gain in weight. His days of excitement became fewer, but not less severe. He was more irritable, ideas of reference became more prominent and in his excitement he would strike down those in his way. He gained some insight into the nature of his past state, explained the origin of certain ideas he had expressed and was discharged, recovered, four months from the beginning of his mental disturbance.

Though in these four groups can be included the large majority of all the protracted cases, there are still unclassified certain cases of undoubted rheumatic psychoses which must be left as atypical. Besides these more protracted cases of mental disturbance there are the acute mental states, seen much more frequently probably by the internist than by the psychiatrist. Of the highly fatal and extremely acute conditions, Trousseau's case, which was responsible for the formation of an apoplectic type in his classification, is the classic example. A male patient, whose mental state had shown nothing unusual, suddenly arose from his bed with the cry of thief, attacked those about him in a blind rage and was dead in less than fifteen minutes. Joffe records a similar case in an electrician thirty-three years old. He gave a history of very excessive alcoholism. His autopsy showed old and recent vegetations on his heart valve flaps and an enlarged fatty liver, which on microscopic examination showed " extreme steatosis and the hepatic cells destroyed as in icterus gravis." The history and the findings in this 
case are hardly such as to warrant this being considered as a pure case of cerebral rheumatism. Though the condition may appear as suddenly as in the two cases mentioned, more frequently the patients have shown for several nights some restlessness, talking in sleep, anxious dreams and mildly delirious periods or more rarely have been unusually indolent and apathetic. Then, as a rule toward the end of the first week or early in the second, there is suddenly in the morning a rapid rise in temperature; the affected joints are no longer painful; the mild muttering delirium vanishes and is replaced by wild frenzy, in which the patient attacks those about him or may jump through the window in an attempt to escape. There is sometimes vomiting and local or generalized convulsive features. The temperature rapidly increases to even $I I I^{\circ}$ and death usually follows in a few hours. Sometimes the frenzy changes to stupor, then coma and death. The prognosis of this class of cases is eminently bad. In Kraepelin's 22 cases the mortality was 82 per cent.

Besides these more striking cases there are all grades of delirious episodes. Many of these are rarely available for psychological observations. A very interesting description of an exceedingly mild aberration is given in Knauer's article. It was a non-alcoholic individual who, in the fifth day of his acute articular rheumatism while on the way to the general hospital, fell into a state of confusion, in which he could not tell where he was, his name or his age. He could not tell where he was sick and made no objection to movements of his swollen joints. He was taken to the Psychiatric Clinic, where he was rather inaccessible, cried and groaned and complained of pains in his head. In a couple of hours he became clearer, recollected that he had not been able to think quite clearly, but still had no appreciation of what had happened. His temperature and joint condition lasted three days longer, but no other mental disturbance was perceptible.

Between such mild clouding of consciousness and the hyperacute conditions just spoken of, there are all gradations. The delirium usually occurs in the latter part of the second week and usually when the disease has run a hard course. About half the number show an intensely violent excitement, occasionally a depressed, agitated state, which soon passes into collapse. They frequently are hallucinated. The mental disturbance may last only a few hours, as the extremely mild case quoted above, but usually from 


\section{MENTAL DISTURBANCES AND ARTICULAR RHEUMATISM [Oct.}

two to six days. The mortality is high, about 52 per cent, death usually occurring in collapse.

It has been noted frequently, in the acutely delirious states particularly, that with the onset of the mental symptoms the joint conditions disappear. This led early to the ingenious idea that, inasmuch as the rheumatic effusion could disappear suddenly only to reappear instantly in another joint, the cerebral symptoms were easily explained by a metastasis of the essential rheumatic condition to the brain meninges. The disappearance of the joint conditions, however, is usually only apparent. The patients will let their limbs be moved with indifference and jump around with impunity, but the swelling and redness usually persists, and if the mental state is transitory, as soon as the patient returns to his normal consciousness the pain perception returns. At autopsy in patients dying in periods where this question could arise the usual pathological changes are present in the joints.

In a reverse direction, it was noted by Griesinger in the cases at his disposal that with the reappearance of the joint symptoms the mental state showed signs of improvement and this generalisation formed one of the conclusions of his paper. Study of the cases available now, however, does not substantiate any such conclusion, and it appears safe to say that in most cases a relapse of the arthritis or any other severe complications, if it has any decided effect, tends to make the mental state worse.

We have purposely avoided as far as possible the relation of chorea to these cases. From the point of view of specificity it seems to us unfortunate that of the 12 cases presented by Knauer five should have been complicated by chorea. To be sure the close relation of chorea to acute articular rheumatism has long been known and was firmly fixed on a scientific basis by the cultivation by Wassermann of a streptococcus from the blood of a young girl dying in a post-rheumatic chorea psychosis and the production from this culture of an acute polyarthritis in experimental animals. Yet chorea may result from other causes and it seems to us that the stand he takes in two of his cases is open to question. The first is a 13 year-old schoolboy who at 9 had an acute endocarditis. Early in May an attack of chorea without temperature or joint involvement. Gradual improvement, so that he was discharged on June 9. Eight days prior to that date an attack of 
erythema exudativum over the whole body, which disappeared in three days. After his discharge from the hospital the chorea became worse. He soon showed definite psychical abnormalities. He became irritable, pugnacious, impulsive, threatened suicide, and was very restless. He quarreled with his schoolmates and was quite unmanageable. He had spells of raving and shrieking, until in one of these spells he was, on December 3, picked up on the streets by the police and taken to the Psychiatric Clinic. He showed little mental abnormality here and he was in January transferred to the Children's Clinic. He shortly developed a fever with acute polyarthritis. On the third day of his fever he had an outburst of transitory violence. Following this, for four or five days he was inaccessible, but gradually returned to his normal level and was discharged recovered at the end of the month. Knauer looks upon this mental state as a recurrent condition dating back to the erythema exudativum, a cutaneous expression of the same infection which seven months later caused the joint affection. His Case Nine is equally open to question, inasmuch as the patient, already of peculiar constitution, besides her chorea, had been definitely abnormal to the extent of alternating excitement and stupor, suggestions of negativism, vivid hallucinations, etc., for several months before the rheumatism. Others of his cases, even though complicated during the course of the mental disturbance by the development of a chorea, are acceptable without debate. He finds in agreement with other investigators that the average age in 100 cases of post-rheumatic chorea was approximately 14 years; of post-rheumatic chorea psychoses approximately 18 years; of postrheumatic psychoses without chorea about 29 years, and theorizes from these considerations that with increasing age the point in the brain attacked by the toxic agent gradually shifts from the lower motor centers to the higher psychical fields. In view of the fact that the post-rheumatic chorea is looked upon as a fairly definite entity, it hardly seems wise to accept such cases as characteristic of what he seeks to prove.

The exact cause or causes of the mental disturbances during the course of acute articular rheumatism are not clear. Many of the delirious episodes during the acute stage of the disease are undoubtedly pure fever delirium and should not be looked upon in any sense as specific. There are those who, without other signs 
380 MENTAL DISTURBANCES AND ARTICULAR RHEUMATISM [Oct.

of psychopathic makeup, regularly show a delirium with only a slight rise in temperature. Such individuals may later develop an endogenous psychosis; this we see not infrequently in our manicdepressive patients. In the hyperpyretic cases, conveniently so called, the increasingly high temperature is simply an expression of the extreme toxæmia which is affecting the nervous mechanism of the heat regulating center as well as the brain cortex. That high temperature of itself is not sufficient to cause the mental symptoms is attested by such observations as Rosenthal's case, with a temperature rising in the first 24 hours to III.4 $4^{\circ}$., and $\mathrm{Da}$ Costa's, with a temperature of $110^{\circ} \mathrm{F}$., without signs of delirium. Whether this toxæmia is purely bacterial in origin is unknown. Kraepelin has utilized in the manufacture of a theory the observations that sometimes in these hyperpyretic cases all signs of joint involvement actually do disappear and suggests that the sudden resorption of this fluid floods the body with an excessive amount of some toxic substance which cannot be excreted or made innocuous fast enough to prevent damage to the cerebral cortex.

In the protracted cases there are numerous additional factors. The prolonged toxæmia, the altered metabolism as a result of this and the physical exhaustion from the disease, together, in many cases, with the added effects of various complications or several relapses of the polyarthritis, all serve to bring about the changes in the cerebral cortex. There are few histological studies according to modern methods of the changes in the cortex in these conditions. Josue and Salamon and Williams have reported their findings, which show changes in the staining capacity of the cells, disappearance of the chromatophilic substance resulting in a pale homogeneous appearance and degenerative changes in the cell nucleus with its occasional entire destruction. Neuronophagocytosis is prominent.

The outcome in the superacute cases is imminently bad. As already stated the mortality is $\mathbf{8 2}$ per cent. In the acute infectious delirium the prognosis is more hopeful, but still serious. Fifty-two per cent of this class die. In the more protracted cases of the late febrile or convalescent period the prognosis is uniformly good for recovery. The course is usually long, from several months to a year. 
The treatment is first that of the primary disease. So long as any indications exist there does not seem to be any valid reason for stopping the salicylates. What therapeutic measures should be taken from the mental aspect depends upon the conditions present. The sitophobia, which is so common and which should be met by tube feeding because of the absolute necessity of building up the general nutrition of the individual, the frequent sudden outbursts of wild frenzy or of suicidal impulses, and numerous other reasons of like character make it highly advisable that the patient be in a hospital and preferably one especially equipped for the treatment of acute mental conditions.

\section{REFERENCES.}

Griesinger : Archiv. f. Heilkunde, Bd. I.

Simon: Archiv. f. Psychiatrie, Bd. IV.

Kraepelin: Archiv. f. Psychiatrie, Bd. XI.

Kraepelin: Psychiatrie, achte Aufl.

Kraepelin: Einführung in die psychiatrische Klinik, zweite Auf.

Wood: Phil. Med. Times, May 30, 1874

Da Costa: Am. Jour. Med. Sci., Vol. 69.

Pribram: Nothnagel's Handbuch, Bd. V.

Osler: Textbook of Medicine.

Bonhoeffer: Handbuch der Psychiatrie, 1910.

Bonhoeffer: Cent. f. Nervenheilkunde u. Psychiatrie, Bd XXXII.

Kleist: Allg. Zeit f. Psych., Bd. LXVII.

Lepine: Lyon Medical, 1908.

Williams: N. Y. Med. Jour., I9I I.

Westphal: Wassermann and Malkoff Berl. Klin. Woch., 1899, No. 29.

Rosenthal: Deut. Med. Woch., 1891, s. 321.

Joffe: Paris These, I908.

Hewlett: J. A. M. A., I913.

Knauer: Zeit. f. d. ges. Neurol. u. Psych. Originalien, I9I4.

Hoppe: Lancet-Clinic, 1909.

Siemerling: Die Deutsche Klinik, 1906. 